\title{
Analyzing the Working Conditions for Female Field Managers Employed by General Contractors
}

\author{
Son, Chang-Baek ${ }^{1} \quad$ Shin, Won-Sang ${ }^{2} \quad$ Lee, Dong-Eun ${ }^{3 *}$ \\ Department of Architectural Engineering, Semyung University, Jecheon-si, 390-711, Korea ${ }^{1}$ \\ Graduate School of Department of Architectural Engineering, Semyung University, Jecheon-si, 390-711, Korea ${ }^{2}$ \\ School of Architecture and Civil Engineering, Kyungpook National University, Buk-Gu, Dae-Gu, 702-701, Korea ${ }^{3}$
}

\begin{abstract}
In recent years, the number of female workers pursuing careers in the construction engineering and management field has increased, despite the fact that the job positions have been traditionally considered as retaining job functions and/or qualities that are more appropriate to male than female. This may be attributed to the fact that the positions also require delicate and/or detail-oriented job functions, which can be successfully performed by female. It is important for project participants to understand the working conditions for female field managers by analyzing their job performance. This study collects expert opinions regarding female's managerial performance on job site. Survey questionnaires were administered to two focus groups, male and female field managers who work for general contractors. This study contributes to encouraging female's social and economic involvement by investigating the challenges they face in the workplace, and provides measures to respond to such challenges.
\end{abstract}

Keywords : female field manager, working condition, job satisfaction

\section{Introduction}

\subsection{Research background and objective}

In the past, marriage prevented female from actively participating in the economy due to child rearing. However, as educational opportunities have expanded and the social roles for female have changed, more and more female have made inroads into professional fields that were once considered solely the realm of male, and the construction field is no exception. Some believe that female managers can handle construction projects in a more

Received : February 2, 2013

Revision received : March 13, 2013

Accepted : March 30, 2013

* Corresponding author : Lee, Dong-Eun

[Tel: 82-51-950-7540, E-mail: dolee@knu.ac.kr]

(c)2013 The Korea Institute of Building Construction, All rights reserved. delicate and detail-oriented manner compared with male managers, and are considered more appropriate for the successful management of a project, as the scale of construction projects becomes larger and more specialized.

Therefore, it is believed that a plan to utilize female workers effectively is necessary for the success of construction projects. To do this, a comparative analysis needs to be conducted to evaluate the working conditions for female field managers and for male field managers, and this can be utilized as fundamental data to establish a plan to resolve the discrimination that might be experienced by female field mangers at a job site.

For this reason, this study aims to perform a comparative analysis by investigating working conditions for the female field managers who are currently working for general contractors from the 
male and the female perspectives, respectively, in order to provide fundamental data that could be used to expand the female workforce in the domestic construction field and raise its social contribution.

\subsection{Research scope and methodology}

The scope of this study was limited to an analysis of the working conditions for female field managers in terms of job satisfaction, promotion policy, facilities, salary policy, type of employment contract, welfare policy and areas of responsibility. In addition, we selected the companies among the top 50 general contractors that had female field managers actually working at a site, and conducted a direct interview and a questionnaire survey of the female field managers.

Due to the recent downturn in the construction business, the subject companies do not currently have as many construction sites as they used to. Notably, there was a relatively small number of construction sites where female field managers are currently working. For this reason, the survey was done on a total of 31 female field managers at 19 construction fields of 13 general contractors, whereas the survey was done on a total of 89 male field managers at 31 construction fields of 24 general contractors.

\subsection{Review on previous studies}

There has been a limited number of studies on female workers in the construction industry compared to studies on female workers in other fields. Jang et al.[1] proposed a plan to utilize female workers to resolve the problem of the lack of a skilled workforce in the construction industry. Son et al.[2] analyzed the design tasks usually done by female, deduced the factors hindering work efficiency and presented an improvement plan. In addition, with respect to the management tasks at a construction site, Son and Kim[3] investigated the current state and detailed management tasks of an apartment construction site, and presented an improvement plan for the establishment of an operation system for field management tasks. Park and Son[4] deduced the business details for each task of a field manager for a general contractor to analyze the importance and the difficulty level of each item, based on which they sought a direction for improvement to raise the efficiency and productivity of a construction project.

However, these previous studies only presented improvement plans based on the problems found and the utilization of a female workforce in the construction industry. There have been no studies conducted on the working conditions for female field managers. Therefore, this study is unique in that it provides fundamental data for the inflow of female field managers in the construction field in the future and an efficient plan for the utilization of these managers by investigating the current state of the work they are in charge of for general contractors.

\section{Trend of female workers' activities in the construction field}

As illustrated in Figure 1, which shows the 5 -year trend of the ratio of female field managers, there was a slight decline in 2007, but has been a gradual increase since 2008. Generally speaking, work in the construction field has been avoided by the younger generation because of its so-called "3D" properties. An increase in the number of female in the construction industry is believed to have helped resolve the workforce shortage to some degree. Therefore, by analyzing the current state of working conditions and of the tasks for the female field mangers, we expect to provide 
fundamental data that can support an increasing inflow of capable female human resources to the construction field.

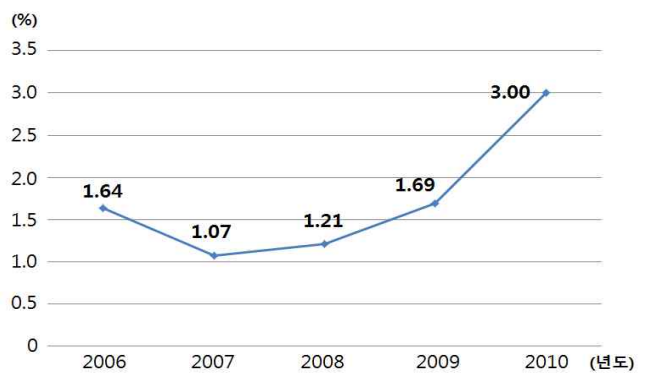

Figure 1. 5-year trend of rate of female field managers on construction job sites

\section{Analysis of the current state of the tasks for female field managers}

A questionnaire survey was conducted for the male and female field managers who are currently working for general contractors to analyze the working conditions for female field managers. The female managers are the subjects directly related with this research, and we investigated their perceptions of their working conditions. The male managers were also investigated, if necessary, to understand the working conditions from the viewpoint of males who have direct observance and experience to perform a comparative analysis.

\subsection{Career choice motivations and job satisfaction}

To the question of what made them choose the job, a majority of the female managers, as indicated in Table 1, answered that they "possess talents related to the field.' This can be interpreted as meaning that female managers believe that they could apply their unique abilities, have a competitive edge and compete against male managers in the construction field. Under the miscellaneous opinions, there were "to gain field $\mathrm{ex}^{-}$ perience' and 'to be promoted to headquarters.' The satisfaction of female field managers was analyzed using a 5-point scale (very satisfied 5, satisfied 4, neutral 3, dissatisfied 2, and very dissatisfied 1). Table 2 indicates the survey results, and the average response was 3.19, which means that a majority of female field managers are satisfied with their job to a moderate level. This may also reflect that female field managers feel their working conditions at a construction site are not satisfactory in several aspects.

Table 1. Female field managers' motivation to pursue the career path

\begin{tabular}{|c|c|}
\hline Reasons & $\begin{array}{l}\text { No. of } \\
\text { Respondents }\end{array}$ \\
\hline $\begin{array}{c}\text { To attempt a career exclusively reserved for } \\
\text { males }\end{array}$ & 1 \\
\hline To develop a career path with good prospects & 2 \\
\hline $\begin{array}{c}\text { Because the respondent possesses talents } \\
\text { related to the career field }\end{array}$ & 15 \\
\hline $\begin{array}{l}\text { Because the job may give the opportunity to } \\
\text { make a social contribution }\end{array}$ & 1 \\
\hline $\begin{array}{c}\text { Because the job is a source of the pleasure } \\
\text { of creating something }\end{array}$ & - \\
\hline Because high salary is provided & 4 \\
\hline $\begin{array}{c}\text { Because no other job opportunities are } \\
\text { available }\end{array}$ & - \\
\hline Other & 8 \\
\hline Total & 31 \\
\hline
\end{tabular}

Table 2. Female field managers' job satisfaction

\begin{tabular}{cc}
\hline Satisfaction & No. of Respondents \\
\hline Strongly dissatisfactory & 2 \\
Dissatisfactory & 2 \\
Neutral & 16 \\
Satisfactory & 10 \\
Strongly satisfactory & 1 \\
Total & 31 \\
Mean & 3.19 \\
\hline
\end{tabular}




\subsection{Job description}

For both female and male managers, the job description was found to be construction engineering and management engineering, as shown in Figure 2. However, the job functions female field mangers can take responsibilities for are shown to be limited compared with those available to male managers. Therefore, the job functions female mangers can be responsible for should be expanded to include more diverse jobs in the future.

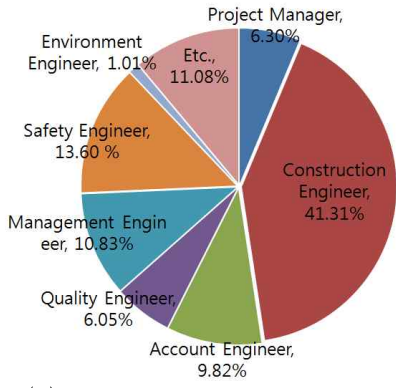

(a)The ratio of job functions handled by male field managers (\%)

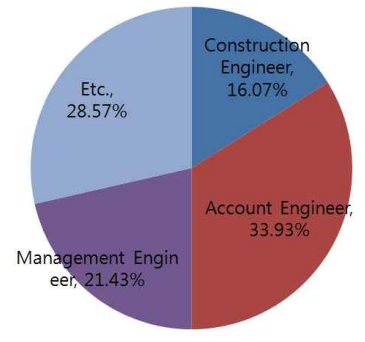
managers(\%) (b) The ratio of job functions handled by female field

Figure 2. The share of site Jobs by the two groups

\subsection{Promotion}

Conventional wisdom holds that in the traditionally male-dominated construction industry, female managers suffer a disadvantage or lag behind. To determine whether or not this was true, we asked female field managers about promotion. Our survey result showed, as shown in Figure 3, that most of the female managers stated that they had a more difficult time getting promoted than male managers.

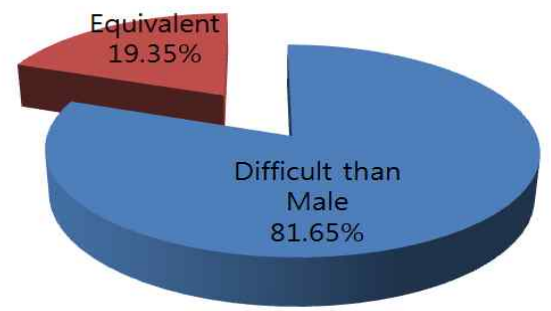

Figure 3. The possibility of being promoted to department head for female field managers
The results of the survey question asking both female and male managers why they think female managers have a harder time getting promoted than male mangers are presented in Table 3.

Table 3. Barriers to promotion faced by female

\begin{tabular}{ccc}
\hline & \multicolumn{2}{c}{ No. Respondents } \\
\cline { 2 - 3 } & Male & Female \\
\hline $\begin{array}{c}\text { Because of the stereotypes that the job } \\
\text { is a male-dominated profession }\end{array}$ & 23 & 12 \\
$\begin{array}{c}\text { Because female has relatively lower } \\
\text { capability to perform the job function } \\
\text { than man }\end{array}$ & 26 & 1 \\
$\begin{array}{c}\text { Because female work less hours than } \\
\text { man }\end{array}$ & 6 & 1 \\
$\begin{array}{c}\text { Because female can carry less workload } \\
\text { than man }\end{array}$ & 6 & 3 \\
$\begin{array}{c}\text { Because female has less interpersonal } \\
\text { skills and connection }\end{array}$ & 13 & 2 \\
$\begin{array}{c}\text { Because female retain incomplete } \\
\text { competence than man }\end{array}$ & 2 & 3 \\
$\begin{array}{c}\text { Because female has less personal } \\
\text { relations that can support them (e.g., } \\
\text { regionalism or graduates, etc.) } \\
\text { Others }\end{array}$ & 2 & - \\
No response \\
Total
\end{tabular}

Among male managers, the most common response was 'because female have a relatively lower capacity to perform the job than male,' followed by 'because of the stereotype that the job is a male-dominated profession.' However, most female managers responded "the stereotype that the job is a male-dominated profession.' To sum it up, construction sites are still considered as male-dominated, and this is a fact that is acknowledged by male managers. It is believed that to break the stereotype, more opportunities should be provided for female managers to prove their capability in the field.

The results of the survey current and target rank of female managers are provided in Table 4. Currently, female field managers mainly work as engineers. In terms of the target rank, about 30\% 
of female respondents wanted a ranking of director or higher, while about $50 \%$ of the females considered an acting department manager or lower rank as their final position. As mentioned earlier, this may be the result of reduced expectations due to their disadvantage in terms of promotion compared with male managers. Therefore, to achieve an inflow of capable female field managers to construction sites, the evaluation method for promotion should be systemized to secure a job rank for female managers, equivalent to males, without discrimination.

Table 4. The current and target ranks of female field managers

\begin{tabular}{ccc}
\hline Ranks & No. Current rank & No. Target rank \\
\hline Field Engineer & 18 & 2 \\
Acting section chief & 5 & 5 \\
Section chief & 2 & 8 \\
Acting department & 2 & 3 \\
manager & & 4 \\
Department & - & 5 \\
manager & & 5 \\
Director or higher & - & 4 \\
rank & 4 & 31 \\
Non-response & 31 & \\
Total & &
\end{tabular}

\subsection{Facilities}

We also surveyed the facilities for female managers and their satisfaction with them. As shown in Table 5, while a female's toilet is installed at almost every site, female's locker and shower rooms, and female's resting lounge are not built on almost all construction sites. Our survey, based on a 5-point scale (very satisfied 5, satisfied 4, neutral 3, dissatisfied 2, and very dissatisfied 1), found that female managers were comparatively satisfied with the toilet, but were greatly dissatisfied with the locker and shower room, and the resting lounge. The working conditions of the construction industry are poor compared with those of other industries, particularly for female workers. To expand the management workforce by increasing the inflow of capable female field managers, there is an urgent need to install and improve the facilities for female.

Table 5. Female's welfare/sanitary facilities on the job site

\begin{tabular}{ccccc}
\hline & \multicolumn{3}{c}{ Whether to Installation } & Satisfaction \\
\cline { 2 - 4 } & Installation & $\begin{array}{c}\text { Non- } \\
\text { installation }\end{array}$ & Total & \\
\hline Female toilet & 29 & 2 & 31 & 3.60 \\
$\begin{array}{c}\text { Female locker } \\
\text { and shower } \\
\text { room }\end{array}$ & 8 & 23 & 31 & 2.95 \\
$\begin{array}{c}\text { Female } \\
\text { resting lounge }\end{array}$ & 7 & 24 & 31 & 3.06 \\
\hline
\end{tabular}

\subsection{Wage policy}

Given that the construction industry is considered male-dominated, we surveyed the current state of wages for female field managers. Our survey found that female managers with equivalent work experience did earn a similar level of wage compared with male managers, as indicated in Table 6. Therefore, female field managers are believed to be more satisfied with wage policy compared to other working conditions, including promotion and facilities.

We asked the female managers who responded that the female managers earned a lower salary than male managers about the level of the wage for the female workers, and it was found that if the salary paid to male managers is $100 \%$, the salary paid to female managers was $79.3 \%$.

Table 6. The salary paid to female field managers

\begin{tabular}{cccc}
\hline \multirow{2}{*}{ Items } & \multicolumn{3}{c}{ No. Respondents } \\
\cline { 2 - 4 } & Male>Female & Male=Female & Male<Female \\
\hline Salary level & 9 & 21 & 1 \\
$\begin{array}{c}\text { Difference } \\
\text { between the } \\
\text { female and } \\
\text { male's } \\
\text { salaries } \\
\text { levels }\end{array}$ & Female's salary corresponds to 79.3 percent of \\
male's salary & \\
\hline
\end{tabular}

\subsection{Type of employment contract}

In terms of type of employment contact, the 
portion of part-time employment has been on the rise. For this reason, we surveyed the types of employment contract held by female field managers. As indicated in Table 7, it was found that the ratio of part-time employment was slightly high among both female and male managers,

Table 7. Employment contract type for female managers

\begin{tabular}{ccc}
\hline \multirow{2}{*}{ Contract type } & \multicolumn{2}{c}{ No. Respondents } \\
\cline { 2 - 3 } & Male & Female \\
\hline $\begin{array}{c}\text { The ratio of part-time to full-time } \\
\text { employment is the same for both } \\
\text { male and female field managers. }\end{array}$ & 33 & 8 \\
$\begin{array}{c}\text { The ratio of part-time of female } \\
\text { managers is higher than that of } \\
\text { male managers. }\end{array}$ & 37 & 11 \\
$\begin{array}{c}\text { The ratio of part-time of male } \\
\text { managers is higher than that of } \\
\text { female managers. }\end{array}$ & 9 & 7 \\
$\begin{array}{c}\text { Both male and female field } \\
\text { managers are employed full-time. }\end{array}$ & 3 & 1 \\
$\quad$ Others & - & 2 \\
$\quad$ Non-response & 7 & 2 \\
$\quad$ Total & 89 & 31 \\
\hline
\end{tabular}

In the question regarding why more female field managers are contracted on a part-time employment basis, male managers mainly responded 'female field managers leave the position after a short period of employment,' and 'the job functions that female field managers are in charge of are appropriate for part-time employment.' On the other hand, among female managers the most common response was that 'female managers leave the position after a short period of employment.'

It seems that most female field managers tend to quit the job after a short period of employment due to child rearing and housekeeping. Therefore, if support plans for female field managers are made, such as a grant to help female workers with children to pay for child care and the operation of a nursery in the workplace, the long-term employment of female managers can be expected and the ratio of part-time employment to full-time employment would be reduced accordingly, which is expected to create a desirable virtuous circle to increase the longer-term employment of the female workforce.

Table 8 . The reasons why female field managers have high rates of part-time employment

\begin{tabular}{ccc}
\hline & \multicolumn{2}{c}{ No. Respondents } \\
\cline { 2 - 3 } Reasons & Male & Female \\
\hline $\begin{array}{c}\text { Because female field managers } \\
\text { leave the position after a short } \\
\text { period of employment, the } \\
\text { company prefers a part-time } \\
\text { employment contract. }\end{array}$ & 21 & 8 \\
$\begin{array}{c}\text { Because the job functions that } \\
\text { female field managers are in } \\
\text { charge of are appropriate for } \\
\text { part-time employment. }\end{array}$ & 21 & \\
$\begin{array}{c}\text { Part-time employment is more } \\
\text { cost-effective. }\end{array}$ & 4 & 1 \\
No particular reason is involved. & 10 & \\
It was adapted without any & & \\
concerns and policies. & & \\
$\quad$ Others & 4 & 2 \\
Non-response & 29 & 13 \\
$\quad$ Total & 89 & 31 \\
\hline
\end{tabular}

\subsection{Welfare policy}

The welfare policy for female field managers including benefits and satisfaction with them was evaluated using a 5-point scale (very satisfied 5, satisfied 4, neutral 3, dissatisfied 2, and very dissatisfied 1), and the results are shown in Table 9. Female field managers were given the benefits of maternity leave, childcare leave and menstruation leave, but were not fully benefited with other leaves. Although they are currently benefited with these leaves, they responded that they were dissatisfied overall with the benefits. It is reality that the welfare policy for the female workers is still lacking in terms of awareness and consideration due to the long male-dominated organizational culture of the construction industry. To the survey question regarding what female managers want the most in a welfare policy, a flexible working system was the most common response, followed by the operation of a nursery in the workplace, and the operation of a female's leadership program. 
Table 9. Welfares and satisfaction

\begin{tabular}{ccc}
\hline Welfare type & Level (\%) & Satisfaction \\
\hline Menstruation leave & $17(56.7 \%)$ & 2.29 \\
Maternity leave & $21(67.7 \%)$ & 2.95 \\
Maternity grant & $12(38.7 \%)$ & 2.73 \\
Childcare leave system & $18(58.1 \%)$ & 3.00 \\
$\quad$ Child support & $12(38.7 \%)$ & 2.70 \\
$\begin{array}{c}\text { Encouragement system } \\
\text { for childbirth }\end{array}$ & $7(22.6 \%)$ & 2.33 \\
Flexible working system & $10(32.3 \%)$ & 2.56 \\
$\begin{array}{l}\text { Operating female's } \\
\text { leadership program }\end{array}$ & $9(29.0 \%)$ & 2.75 \\
$\begin{array}{c}\text { Operating a nursery in } \\
\text { the workplace }\end{array}$ & $9(29.0 \%)$ & 2.88 \\
\hline
\end{tabular}

\section{Difficulties at a construction site faced} by female managers

The difficulties faced by female field managers at a site are presented in Table 10. 'Working time(heavy workload)' was the most common response, followed by 'working conditions on the site(including facilities),' 'adjustment to the unique culture of a construction site,' 'promotion problem,' and 'welfare policy,' in that order. This may reflect the reality that the female managers feel that the working time is too long for them to take because they need to take care of their child(ren) in their home, lack facilities for female workers and are disadvantaged in terms of promotion.

Table 10. Difficulties faced at construction sites by female managers

\begin{tabular}{cc}
\hline Difficulties & No. Respondents \\
\hline Type of employment contract and Condition & 4 \\
Salary policy & 2 \\
Promotion policy & 5 \\
Ability to perform the job(The degree of & - \\
difficulty that the job provides) & 5 \\
Welfare condition & 9 \\
Work environment in the field (convenience & 1 \\
facilities etc.) & 16 \\
Opportunity for education and/or training & 2 \\
Excessive office hours and workload & 4 \\
Discrimination by male employees & 6 \\
Conflicts between co-workers & 2 \\
Strong culture of construction site & 6 \\
Others & 62 \\
Non-response & Total
\end{tabular}

\section{Conclusion}

In this study, a comparative analysis of working conditions for female field managers was performed from both the female and male perspectives to provide fundamental data to support an increase in the flow of capable female field managers to the construction field, and to develop a plan for the efficient utilization of female workers. The findings of this research can be summarized as follows:

1) The most common motivation among female field managers for choosing their career was that they have talent in field management, but their job satisfaction was found to be relatively low.

2) The salary paid to female managers was shown to be similar to that paid to male managers. However, in terms of promotion, facilities, and type of employment contract, working conditions were disadvantageous for female managers compared with male managers. In terms of the welfare policy, female managers were not fully benefited, and were dissatisfied overall with the welfare system.

3) The difficulties faced by female managers on the site were described as heavy workload required for long working time, insufficient facilities exclusive for female workers, unfair treatment in promotion, and an insufficient welfare policy for female workers.

4) To utilize capable female field managers in the future, sufficient facilities for female should be built, and an evaluation system for promotion that secures a status for female workers equivalent to that of male workers should be prepared. In addition, concrete support plans for the long-term employment of female managers should be established, 
including a flexible working system, and the operation of a nursery in the workplace.

This study has some limitations in that the number of female field managers sampled is fairly small, and it does not provide a concrete improvement plan. To address these limitations, a concrete improvement plan should be sought in a future study that can be utilized efficiently to help promote the gradual inflow of capable female human resources to the construction field.

\section{References}

1. Jang SY, Yoon JS, Paek JH. A Study on the Efficient Application of Female Crafts in a Changing Construction Environment. Proceeding of Architectural Institute of Korea 2004 Spring Conference; 2004 Apr 24; Seoul National University. Seoul (Korea): the Architectural Institute of Korea ; 2004. p. 435-8.

2. Son CB, Lee DJ, Seo BK. A Study on Investigation of Female' s Work Performance in Design Stage, Journal of Architectural Institute of Korea. 2011 Dec;13(4):323-31.

3. Son CB, Kim BR. Improvement of the Field Management Work and Operation System in the Apartment Construction. Journal of Architectural Institute of Korea. 2006 Jun;22(6):165-72.

4. Park KH, Son CB. Analyzing the Level and Influence Factors for Work Performance of Field Managers in General Construction Companies. Journal of Architectural Institute of Korea. 2010 May;11(3):115-24.

5. Ministry of Employment and Labor. Female and Find a Job. Gwacheon (Korea): Ministry of Employment and Labor; 2011. p. $52-4$. 